\title{
AS POLÍTICAS DE SAÚDE NO BRASIL: RECONSTRUÇÃO HISTÓRICA E PERSPECTIVAS ATUAIS
}

Maria Rita Bertolozzi*

Rosangela Maria Greco*

BERTOLOZZI, Maria Rita; GRECO, R. M. As políticas desaúde no Brasil: reconstruçăo histórica e perspectivas atuais. Rev.Esc.Enf.USP, v.30, n.3, p.380-98, dez. 1996

A partir de revisão bibliográfica, as autoras discorrem sobre a questão das políticas públicas de saúde no Brasil, procedendo a uma re-leitura do processo. Apontam para a importância da discussão sobre a questão nos cursos de graduação em Enfermagem.

UNITERMOS: Políticas de saúde. História da saúde no Brasil.

\section{1 - A Título de Introdução}

O presente artigo busca responder as necessidades que emanam do cotidiano do ensino da temática sobre as políticas de saúde no Brasil, tendo por finalidade subsidiar o desenvolvimento do processo ensino-aprendizagem de alunos do curso de Enfermagem. Com isto se pretende que os estudantes tenham elementos para compreender as articulaçōes entre os processos econômicos, políticos e as práticas de saúde no país, a partir do conhecimento das raízes históricas das políticas de saúde que foram sendo implantadas ao longo da constituição do Estado brasileiro.

É fundamental ressaltar a importância desta temática para a Enfermagem, uma vez que, enquanto prática social, tem como finalidade o monitoramente dos perfis epidemiológicos com vis tas à sua transformação (QUEIROZ; SALUM, 1994 a, b, c). Assim, entende-se que a intervenção em enfermagem deve se dar, segundo QUEIROZ; EGRY (1988), nas 3 dimensões da realidade: a estrutural, que corresponde ao aparato jurídico-político e ideológico, além da infra-estrutura econômica; a particular - que se refere aos processos relativos aos grupos sociais; a singular, que se relaciona à expressão bio-psíquica no corpo individual e social.

Des ta forma, para que a enfermagem responda à sua finalidade no campo da saúde coletiva, há que se ter como pano de fundo a articulação entre

Enfermeira. Professor Assistente do Departamento de Enfermagem em Saúde Coletiva da Escola de Enfermagem da Universidade de São Paulo. 
as três dimensões anteriormente apontadas. Nesse sentido, a compreensão da forma como se estruturam as políticas sociais e, entre elas as políticas de saúde, é fundamental para que ocorram as intervenções.

Além das questões anteriormente colocadas, a razão que nos leva a discorrer sobre a questão das políticas de saúde no Brasil, já tratada sob as mais diversas formas pelos mais diferentes autores, se deve a uma necessidade de proceder a uma re-leitura do processo e recolocá-lo, a luz dos mais recentes fatos advindos do processo de Reforma Sanitária e dos desdobramentos do projeto político neoliberal sobre o setor saúde.

Para tanto, a aproximação ao objeto - história das políticas de saúde - foi feita a partir de uma análise reflexiva da produção teórica existente no campo, sem a pretensão de tornar o presente estudo como acabado. Nesse sentido, são princípios que norteiam esta reflexão: - a transitoriedade, ou seja, a noção de que nada é eterno; - a compreensão de que todo fenômeno (econômico ou social) é produto das ações humanas; - a concepcão da realidade social como uma estrutura orgânica - assim, nenhum aspecto ou dimensão pode ser deixada de lado sem que se reporte à totalidade (EGRY, 1994).

Para a compreensão da estruturação das políticas de saúde resgatamos a divisão didática utilizada por ROSSI (1980), que distingue os períodos da história em: colonial, primeira República até a Revolução de 30 e o populismo de 45 a 60 . Foram ainda incluídos capítulos referentes aos períodos relativos aos anos 60 até o fim da Ditadura Militar; e da Nova República até a atualidade.

\section{2 - O Periodo Colonial}

Nesse período, o Brasil se encontrava à margem do capitalismo mundial, submetendo-se econômica e politicamente à metrópole Portugal, sendo que a exploração econômica se dava através de ciclos - do pau-brasil, da cana de açúcar, da mineração, do café.

O ciclo do pau-brasil não chegou a determinar uma estruturação de classes na sociedade brasileira, pois se caracterizou basicamente pela extração vegetal. Já o ciclo da cana de açúcar, se distingüiu pela presença de grandes propriedades escravistas, que exigiam grandes aplicações iniciais de capital, com enorme concentração de renda nas mãos dos senhores, donos das propriedades, ao lado da exploração da mão de obra de trabalhadores trazidos da África. Esse ciclo determinou a formatação da sociedade constituída pelos pólos - senhor e escravo (ROSSI, 1980).

Em relação ao ciclo da mineração, este proporcionou um maior desenvolvimento comercial e urbano com grande crescimento demográfico e uma menor concentração de renda nas mãos dos senhores, a partir da emergência de estratos sociais que configuraram os primeiros contornos da sociedade de classes (ROSSI, 1980). 
O ciclo do café dinamizou o mercado interno com o início das diferentes modalidades do trabalho assalariado. Esse fenômeno foi representado pela ocupação efetiva do solo, o que exigiu uma infra-estrutura que necessitava de financiamento, o qual foi concretizado no exterior. (O) café era produzido com o objetivo de ser exportado, assim como os produtos que foram os protagonistas dos ciclos anteriores. A exploração se fazia pela burguesia local que, no período da República, passou a assumir o controle do desenvolvimento social e acabou por re- estruturar a formação da sociedade capitalista brasileira.

Dado que inexistia um sistema de saúde formalmente estruturado, as ações eram de caráter focal, sendo que grande parte da população utilizava-se da medicina de "folk", enquanto que os senhores do café tinham acesso aos profissionais legais da medicina, que eram trazidos de Portugal.

Nessa época foi constituída a Academia Real de Medicina Social, na Bahia, que tinha como objetivos: a proteção da saúde da população segundo os modelos europeus e a defesa da ciência, o que contribuiu para a construção da hegemonia da prática médica no Brasil.

Nesse momento, a Saúde Pública no Brasil passou a ser calcada em intervenções engendradas na corrente de pensamento do Sanitarismo, que se operacionalizava no âmbito urbano das cidades, com a comercialização e transporte de alimentos e cobertura dos portos marítimos (ROSEN, 1994). Essas medidas eram promovidas pontualmente sob a forma de campanhas, as quais eram abandonadas assim que se conseguiam controlar os surtos presentes na época.

\section{3 - A primeira República até a Revolução de 30}

Esse período foi marcado pela hegemonia do café com predominância de grupos oligárquicos regionais. Em 1888, com a Abolição da Escravatura e com a conseqüente crise da mão de obra escrava, intensificaram-se as correntes imigratórias provenientes, principalmente, da Itália, Espanha e Portugal (ROSSI, 1980).

Com a vinda de incontável número de pessoas, as condições sanitárias para a sua recepção e permanência no Brasil tornaram-se cada vez mais difíceis. Esse fato, aliado à falta de políticas sociais e de saúde pertinentes, acabou por resultar na eclosão de epidemias de febre amarela e peste bubônica, dentre outras.

Com a Proclamação da República elaborou-se a Constituição que assinalava a preponderância dos grandes Estados nas decisões nacionais.Assim, o poder centralizou-se nos Estados produtores de café da região centro-sul, instalandose a política do "café com leite". Essa Constituição incorporou a saúde como uma área de âmbito estatal estabelecendo sua estrutura e locais de atuação (IYDA, 1994). 
No governo de Rodrigues Alves desencadearam-se ações que tiveram como vertente a chamada "Higienização". Através da figura de Osvaldo Cruz, a questão sanitária passou a ser tomada como uma questão política. Como exemplo, podese verificar a lei sobre a vacinação e re-vacinação contra a varíola, no ano de 1904, processo que gerou uma série de revoltas no âmago da população civil contra o sentido militar imputado à campanha (IYDA, 1994).

Com a criação do Departamento Nacional de Saúde Pública que visava a extensão dos serviços de saneamento urbano e rural, além da higiene industrial e materno-infantil, a Saúde Pública passou a ser tomada como questão social. Datam dessa época os primeiros encontros de sanitaristas que bradavam por soluções mais eficazes no que tocava às questões de saúde. Esse movimento sanitário difundiu a necessidade da "educação sanitária" como uma estratégia para a promoşão da saúde e o conteúdo dos discursos era permeado por uma intensa fermentação de ordem liberal (BRAGA; PAULA, 1987).

Na ocasião, os trabalhadores mais articulados politicamente lutavam pela organização das Caixas de Aposentadorias e Pensões (CAPs), que se constituíram em embrião do Seguro Social, correspondendo ao primeiro período da história da Previdência brasileira. As CAP's foram regulamentadas através da Lei Elói Chaves (BUSS, 1995) e concediam benefícios pecuniários, nas modalidades de aposentadorias epensões, bem como na prestação de serviços do tipo de consultas médicas e fornecimento de medicamentos. Para tanto, foi criado um fundo constituído pelo recolhimento compulsório do empregado: $3 \%$ do salário; do empregador: $1 \%$ da renda bruta das empresas o da União: 1,5\% das tarifas dos serviços prestados pelas empresas (CORDEIRO). 1981).

A rápida expansão das ('APs fez com que ocorressem modificações, principalmente aquelas relacionadas às fontes de financiamento. Cabe ressaltar que des de o início, o sistema previdenciário não foi baseado no conceito do direito à previdência social, inerente à cidadania, mas considerado um direito contratual, baseado em contribuições ao longo do tempo (POSSAS, 1981).

Com a crise do padrão exportador capitalista e o conseqüente aumento da dívida externa acirraram-sc os confrontos entre os republicanos e os liberais. Esse fenômeno, aliado à crise mundial do café de 1929, afetou de forma contundente a economia brasileira, criando condições propícias para a Revolução de 1930. Nela, frações de oligarquias, o tenentismo e as classes médias urbanas, modificaram a estrutura de poder. diminuindo o poder oligárquico e aumentando o poder dos estratos sociais pertencentes à burguesia. O êxodo rural, decorrente da bancarrota do café, impulsionou o processo de industrialização e urbanização. Desta maneira, os surtos epidêmicos, que já se faziam presentes, se intensificaram, devido à piora das condições de vida, decorrentes principalmente, do excesso populacional e da falta de infra-estrutura sanitária (ROSSI, 1980).

O Estado Novo, marcadamente populista, absorveu os movimentos dos grupos e respondeu às suas reivindicações através da criação do Ministério do Trabalho e dos Institutos de Trabalhadores. Com isso, o Estado respondia às 
pressões concentrando o poder decisório e concedendo medidas distensivas como as aposentadorias e pensões.

Nesse periodo delineou-se uma política nacional de saúde através da criação de estruturas como o Ministério da Educação e Saúde. Vale dizer que o caráter dessa política continuou sendo restrito, pois limitava-se apenas à cobertura de certos segmentos de trabalhadores.

No que toca aos programas de Saúde Pública, eles voltavam-se para a criação de condições sanitárias mínimas que favoreciam a infra-estrutura necessária para suportar o contingente migratório. No entanto, permaneciam via de regra, limitados pela opção política de gastos do Estado e pelo dispendioso modelo sanitarista adotado (campanhista).

A grande aceleração do ritmo industrial com a expansão de investimentos que se seguiu, fez com que o Estado respondesse as reivindicaçoes da classe trabalhadora, através do estabelecimento do salário mínimo, que se limitava aos gastos para a sobrevivência. Isso, ao lado da intensa inflação da época, acentuou a piora das condições de vida, fenômeno que se refletiu nas demandas por saúde e assistência médica. Os Institutos de Assistência Previdenciária (IAPs) que, a princípio, não se dispunham a fornecer esse tipo de cobertura, começaram a diferenciar-se em suas estruturas, prestando serviços no âmbito da assistência médica.

$O$ crescimento das desigualdades sociais entre as diversas categorias de trabalhadores, no que diz respeito à legislação, recursos financeiros e condições de trabalho, refletia o perfil da estratificação social que caracterizava a sociedade. A aceleração do crescimento industrial aumentava a preocupação com a manutenção da força de trabalho em condições de produção, bem como na sua reintegração rápida ao processo de produção. Para responder a essas demandas, várias instituições de trabalho passaram a criar serviços de atendimento ambulatorial, de caráter terapêu tico e. alguns, em nível de reabilitação (IYDA, 1994).

Necessário se faz dizer que, paralelamente, desenvolvia-se a indústria de fármacos, fato que, em consonância ao objetivo da reintegração da força de trabalho à produção, leva a pensar que isso se constituiu em mais um poderoso álibi para a progressão da atenção de caráter curativo, em detrimento das ações de prevenção.

\section{4 - O Populismo de 45 a 60}

A crise econômica e política, agravada com o final da Segunda Grande Guerra e com a queda de Getúlio Vargas se seguiu um período de liberalização do regime político. Esse período se caracterizou pelo aumento dos salários, pela reativação da legislação trabalhista, pela reforma partidária e as negociações para a instalação de novo pacto social. 
No entanto, com o presidente General Eurico Dutra ocorreu nova intervenção nos sindicatos e partidos, além da declaração da ilegalidade do Partido Comunista Brasileiro e concomitante união dos partidos de centro. No que toca a política externa, nesse momento, se consolidava uma forte aliança com os Estados Unidos da América.

Com o plano SALTE (Saúde, Alimentação, Transporte e Energia), Dutra apresentava a questão da saúde como uma de suas prioridades, mas a Saude Pública, ainda que elevada à condição de "questão social", nunca esteve verdadeiramente entre as opşões prioritárias da política de gastos do governo (ALENCAR et al, 1985).

Na ausência de novas lideranças políticas e com a divisão dos partidos, Getúlio Vargas acabou por vencer as eleições com ampla margem de votos. A população das camadas sociais médias e baixas da zona urbana, nessa época, não agia em função dos interesses de classe, mas como grande massa indiferenciada. Isso resultou em extrema pulverização do comportamento político dos trabalhadores os quais, na ausência de canais como associações, partidos ou outras organizações, tenderam a estabelecer uma relação carismática em relação aos grupos superiores.

Foi nesse clima de barganhas e de pressões que a assistência médica se estendeu a todos os Institutos de Aposentadoria e Pensões (IAPs), antigas Caixas de Aposentadorias e Pensões, que buscavam a uniformização dos direitos e procedimentos. Isto foi garantido através da realização do I Congresso Nacional de Previdência Social que abriu espaço para a posterior aprovação da estatização do seguro contra acidentes de trabalho. No entanto, essa uniformização, apesar de conciliar duas tendências: aquela que atendia aos trabalhadores prejudicados pela diferenciação dos regimes previdenciários e, aquela que respondia aos interesses políticos dos IAPs, foi revogada pelo Presidente Café Filho.

Nessa época foi criado o Ministério da Saúde, com uma estrutura de caráter extremamente frágil, cabendo-lhe a menor fração do orçamento do antigo Ministério da Educação e Saúde, ou seja, um terço do imposto sobre a Educação e Saúde. No plano econômico, tinha início a segunda etapa do processo de industrialização, com a produção de bens de capital, máquinas e equipamentos que requeriam vultosos investimentos. No plano político, ocorria um acirrado embate entre os "Nacionalistas" que combatiam o capital estrangeiro e os "Desenvolvimentistas" que defendiam a expansão industrial, mesmo que com capital estrangeiro.

Com a coligação Nacional-Desenvolvimentista do Presidente Juscelino Kubitscheck, a economia abriu-se ao capital estrangeiro e iniciou-se grande pressão por parte dos empresários no que toca à eficiência das indústrias. No campo da saúde, o Congresso de Hospitais, ocorrido nessa época, respondeu a essas demandas, instituindo os serviços médicos próprios das empresas. Encontrava-se aí uma nova configuração da prestação privada de serviços de saúde, através da emergência da medicina de grupo, que se constituiu em um 
dos lastros para a implementação das políticas neoliberais no âmbito do setor saúde na atualidade (BRAGA; PAULA, 1987).

$O$ final do governo de Juscelino evidenciava um intenso crescimento da inflação, do movimento sindicalista e do movimento estudantil. Para substituir Juscelino, foi eleito Jânio da Silva Quadros, que buscava credito internacional para superar a crise interna, além de colocar-se em uma posição "neutra" frente à política mundial no que tocava às questões entre os países capitalistas e socialistas.

\section{5 - De 1960 até a o fim da Ditadura Militar}

Após sete meses de governo, Jânio renunciou e assumiu o vice-presidente João Belchior Marques Goulart - Jango, que sofreu grandes pressões para não tomar posse, uma vez que suas ligações com os esquerdistas semeavam a desconfiança dos setores conservadores.

No que se refere ao setor saúde, em 1963, foi realizada a III Conferência Nacional de Saúde, instituída por lei já em 1937, com o objetivo de oferecer orientações sobre as políticas de saúde. Essa Conferência definiu como ideologia da saúde, a do desenvolvimento econômico, baseada que estava na racionalidade do planejamento, na produtividade e na distribuição de riquezas. Estes últimos eram principios tidos como "fontes de saúde" (ROSSI, 1980).

Foi nessa época que se registrou a maior participação do Ministério da Saúde no orçamento global da união, apesar das grandes tendências à sua diminuição.

João Goulart promoveu importantes reformas de base administrativa, além da proposição de reforma agrária radical, estatização do abastecimento, nacionalização dos monopólios estrangeiros, bem como controle direto sobre o sistema de livre iniciativa e propriedade privada capitalista.

Mas, com ogolpe de 64, o poder foi assumido pelas Forças Armadas. Editouse o Ato Institucional-1, que suspendeu as garantias constitucionais, permitindo a cassação de mandatos e suspendendo direitos políticos. Além disso, foram extintas todas as organizações que exigiam reformas de base, como o Comando Geral dos Trabalhadores e as Ligas Camponesas (ALENCAR et al, 1985).

Foi nesse contexto que emergiu o movimento sanitário no interior das universidades, como decorrência da exclusão da participação dos trabalhadores e técnicos no processo decisório das políticas de saúde, as quais eram tomadas pelos governos autoritários em seu próprio benefício. Assim, a Universidade passou a ser o espaço onde era possivel a contestação às práticas do regime de então (ROCHA, 1988; TEIXEIRA, 1989).

O momento era favorável à definição de um desenvolvimento restaurador da economia baseado na livre empresa e no saneamento das greves. O General 
Castelo Branco, que foi escolhido como presidente, assumiu com um projeto que fortalecia o Executivo e a segurança do Estado, criando o Serviço Nacional de Informações.

A política econômica adotada levou ao aumento da produtividade. Assim, a jornada de trabalho foi ampliada de oito para, aproximadamente, treze horas diárias. A isso se somou a baixa do poder aquisitivo do salário mínimo, seguida de uma elevada concentração de renda para uma parcela da população (ROSSI, 1980).

Dentro desse contexto político centralizador e importado do modelo econômico norte-americano. colocou-se em prática a metodologia do Planejamento, que se apresentava como um meio de intervir nos setores sociais, através do estabelecimento de ações virtualmente técnicas, paralelamente ao controle do conflito de classes.

Na saúde, as políticas de Planejamento reforçaram a privatização dos serviços médicos, através da compra de serviços pela Previdência, sob a forma de unidades de serviço. As palavras de ordem eram a produtividade, o crescimento, a desbu rocratização e a descentralização da execução de atividades (BRAGA; PAULA, 1987).

É necessário levantar um outro ponto importante, ou seja, que a primeira medida do Ministério do Trabalho em 1964, foi a intervenção nos Institutos de Aposentadorias e Pensões, suspendendo a participação dos representantes dos empregados e empregadores no desenvolvimento dos programas de saúde. As conseqüências dessa medida se fizeram sentir, em 1967, com a criação do Instituto Nacional da Previdência Social (INPS), o qual unificou todos os Institutos, concentrando recursos financeiros e ampliando a compra de serviços da rede privada.

É importante notar que o Golpe de 64 , ao ser analisado do ponto de vista estritam ente econômico, não representou nenhuma mudança radical no quadro já instalado, apenas aprimorou e consolidou o modelo implantado desde 1955. Dentro desse cenário, os interesses estavam centrados no favorecimento da grande empresa através do arrocho salarial. Como justificativa legitimadora para tal, se advogava o combate à inflação e iniciou-se o longo período chamado de "milagre econômico".

Uma das características desse período foi a extrema concentração de renda, explicada parcialmente pelo crescimento das indústrias de bens de consumo duráveis, em detrimento daquelas de bens de consumo não duráveis, que ficou estagnada. Outra característica foi a expansão do sistema de crédito ao consumidor com a participação da classe média no mercado dos bens duráveis. Dois outros elementos importantes foram a abertura externa da economia, através do comércio e o maciço investimento estrangeiro no país, além do papel das empresas estatais na indústria pesada, que passou a garantir a acumulação de capital através da modernização e da dinamização das empresas, como a PETROBRÁS e a ELETROBRÁS. 
Nesse período, o Produ to Interno Bruto (PIB) cresceu 10\% ao ano e cerca de $5 \%$ da população de maior renda, teve sua participação aumentada em mais de $10 \%$, enquanto que, os $80 \%$ mais pobres, tiveram sua renda diminuida em mais de 10\% (ALENCAR et al, 1985).

Foi nesse momento que o INPS passou a ter o terceiro orçamento da nação, ocupando o espaço primordial da prestação da assistência médica. Paradoxalmente a esse quadro, houve no INPS, um déficit orçamentário por conta das inúmeras fraudes que ocorreram na compra de serviços privados de assistência à saúde mascarando, de fato, o volume de unidades de serviço. Ainda nesse momento, ocorreu a expansão da cobertura da assistência médica aos trabalhadores rurais, empregados domésticos, autônomos e para os casos de acidentes de trabalho.

No final de 1973, o modelo econômico e político começou a mostrar sinais de falência em decorrência das inúmeras contradições internas que eram inerentes à sua própria lógica. Além disso, a queda das elevadas taxas de crescimento econômico, retirava do regime político o precário "status" de legitimidade popular que buscava molilizar.

No que se refere à saúde, em 1974, foi criado o Ministério da Previdência e Assistência Social, centralizando e reforçando ainda mais a dominância do modelo clínico assistencial e curativista. Na verdade, justificou-se essa medida pela importância política e financeira que o antigo INPŚ tinha no cenário da época.

Ao mesmo tempo foi criado, pela Lei $\mathrm{n}^{\circ} 6168$ de 09.12 .74 , o Fundo de Apoio ao Desenvolvimento Social (FAS), que representou importante estratégia de ação do Estado na área social, ao apoiar financeiramente o desenvolvimento de programas e projetos de interesse do setor público nas áreas de saúde e saneamento, educação, trabalho, previdência e assistência social, além de projetos de caráter social para pessoas físicas junto ao setor privado (BRAGA; PAULA, 1987).

Os recursos do FAS eram orientados para a lógica da lucratividade, ao criar e/ou fortalecer, através do Estado e, por meio de recursos públicos, uma burguesia empresarial nacional. () grau de distorções na utilização desse Fundo foi patente, na medida em que, destinado a financiar projetos prioritariamente de interesse coletivo, foi sistematicamente utilizado com a finalidade de expandir o setor privado (OLIVEIRA; TEIXEIRA, 1985).

Em 1975, como resultado da V Conferência Nacional de Saúde, foi regulamentada a Lei 6.229 de 17 de julho, que criou o Sistema Nacional de Saúde, o qual legitimava e institucionalizava a pluralidade institucional no setor. Através dessa Lei foram definidas as responsabilidades das várias instituições, cabendo à Previdência Social, a ass istência individual e curativa, enquanto que, os cuidados preventivos e de alcance coletivo ficaram sob a responsabilidade do Ministério da Saúde e das Secretarias Estaduais e Municipais de Saúde. 
A partir do Governo Geisel. com os sintomas de fim do período de crescimento e com a queda real do PIB, tratou-se da reconversão do modelo econômico e da promoção de rearticulações necessárias com a finalidade de preparar os mecanismos para um novo patamar de acumulação.

O período marcou o fim do "milagre econômico" cujos efeitos se faziam sentir no setor saúde atraveśs da crise no padrão de prestação de serviços da rede pública e da previdência social, além do privilégio dos produtores privados nos serviços de saúde.

O quadro epidemiológico que passou a evidenciar-se mostrava a coexistência de doenças infecto-contagiosas e doenças crônico-degenerativas. Alem disso, enfermidades como doença de (hagas, esquistossomose e malária, dentre outras. que incidiam preponderantemente na zona rural. passaram a assolar também as cidades (BRA( A. PAULA, 1987).

Em decorrência-disso, aumentou-se a demanda por consultas médicas ambulatoriais e foram propostos programas que tiveram um impacto político importante, como foi o caso do Programa Nacional de Alimentação e Nutrição (PRONAM) e Programa de Interiorização das Açoes de Saúde e Saneamento (PIASS). Tratavam-se de programas voltados, na teoria, para a atução preventiva, na tentativa de buscar eliminar as condiçoes causadoras das enfermidades. $O$ PRONAM estava sendo lançado numa segunda tentativa e, desta vez, não mais centrava suas ações sobre a industrialização de alimentos. mas sim tinha em vista a compra de insumos o o estímulo a oferta de alimentos básicos. Já o PIASS propunha-se a implementar o operar uma estrutura básica de saúde e saneamento.

Em 1977, efetivou-se mais um movimento burocrático administrativo, na tentativa de promover a reordenação do sistema de saúde, com a criação do Sistema Nacional de Previdência e Assistência Social (SINPAS'), que congregava diversas entidades previdenciárias, comoo Institu to de Administração Financeira (IAPAS), que gerenciaria o Fundo de Previdência de Assistência Social, o INPS - a quem competiria a concessão de benelícios e outras prestações em dinheiro, além de programas assistenciais -. o INAMPS - que se responsabilizaria pela prestação de assistência médica individual aos trabalhadores urbanos e rurais , além da Fundação Legião Brasileira de Assistência - voltada para a prestação de assistência social à população carente. da Central de Medicamentos (CEME) e da Fundação Nacional do Bem Estar do Menor, dentre outras.

Esse movimento justificava-so pela racionalização e reorganização da saúde. Mas, a sua implantação repercutiu de forma totalmente diferente das proposições, isto é, acabou por fragmentar os poderes e dividiu para diversos organismos as diferentes tarefas da Previdência.

No final do Governo Geisel era intenso o movimento de oposição que se expressava através de atos públicos. da imprensa. das forças de oposição e das forças populares que se encontravam em processo de reorganização. 
O governo seguinte do Presidente General João Batista Figueiredo, manteve a política na qual o Executivo permanecia como árbitro supremo. A atuação reivindicativa das correntes anteriormente mencionadas, impulsionou o movimento pela anistia. Paralelamente, realizou-se a reforma partidária, que teve por objetivo a divisão da oposição. Isso trouxe como conseqüência, a formação de vários partidos políticos, dentre eles. o Partido dos Trabalhadores, que objetivava a organização das massas populares em torno de interesses definidos pelos próprios trabalhadores.

No início dos anos 80, com a crise linanceira no setor da saúde, que se expressava na seguridade social e no modelo privatizante, a proposta do movimento sanitário apresentava-se como forte reação às políticas de saúde implantadas, além de emergir como uma alternativa concreta para a reformulação do sistema nesse campo. () movimento sanitário que remonta aos primeiros anos da Ditadura Militar. difundia um novo paradigma científico com a introdução das disciplinas sociais na análise do processo saúde-doença. Através delas, o método histórico-estrutural passou a ser utilizado no campo da saúde, buscando compreender processos como a "determinação sccial da doença" e a "organização social da prática médica" (TEIXEIRA. 1989).

Em conseqüência do acirramento da criso política. um grupo de técnicos, composto por representantes do Ministorio da Saúde e do Ministério da Previdência e Assistência Social. formulou um Programa, o Prev-Saúde Programa Nacional de Serviços Básicos de Saúde. Esì teve como objetivos gerais, a reestruturação e ampliação dos serviços de saúde, saneamento e habitação. Tinha como pressupostos básico a hierarquizașão das formas de atendimento, de forma tal que a atenção primária se constituísse na porta de entrada dos clientes no sistena de saúde. Alom disso. colocavam-se também como pressupostos básicos, a participação comunitária, a integração dos serviços existentes (público e privado) e a regionalização definida por área e população.

Devido às suas propostas. consideradas por muitos como "progressistas", esse projeto foi rejeitado e severamente mutilado. Posteriormente, foi constituído o Conselho Nacional de Administração de Saúde Previdenciária (CONASSP) com o objetivo de reorientar as proposiçoes do Prev-S'aúde, para que fossem reduzidos os custos da assistência médica. É importante mencionar que a criação desse Conselho foi feita de forma bastante autoritária, pois não contemplava na sua composição, a participação expressiva de trabalhadores da saúde e da comunidade.

() plano proposto pelo ('onselho representava um reforço nas políticas racionalizadoras e na organização da assistência médica pela Previdência. Apresentava como princípios, a priorização das ações primárias com ênfase na assistência ambulatorial, a integração das instituições nos três níveis - federal, municipal e estadual - a partir de um sistema regionalizado e hierarquizado, bem como a utilização plena da capacidade de produção e a participação complementar da iniciativa privada. 
$\mathrm{Na}$ introdução do Plano. a Governo assumiu a crítica ao modelo de saúde previdenciária vigente. lazendo com que o mesmo viesse a representar uma opção de política de saúde, o que deu início ao proesso de mudanças na medicina privada e mercantil. Na impossibilidade de conciliar os interesses e adiar a solução das questões emergentes. o ( Coverno constituiu uma proposta, o Plano de Ações Integradas de Saúde (AIS). como uma estratógia governamental, que contemplava interesses municipais o estaduais. e que conferia maior racionalidade aos serviços básicos do setor público. através do estabelecimento de convênios com o Ministério da l'revidência o Assistência Social.

Na rede pública as $\Lambda I S$ reproduziram o princípio da produtividade, através da concepção de pagamento por produção. $\Lambda \mathrm{lem}$ disso, esse plano tinha como princípios, a integração entre as ações e instituições. a regionalização, a hierarquização, o repasse do recursos da previdôncia, alem da descentralização do planejamento e da administração.

Apesar da vontade política de certos setores no sentido de expandir rapidamente os seus princípios. o que se verificou foi uma lenta adesão dos municípios ao convênio. Essa morosidade era decorrente, além de outras causas, da carência de informações para a definição do Plano de $\Lambda$ plicação Municipal, bem como e, acima de tudo, pela postura do INAMPŚ quo impunha determinadas exigências.

\section{6 - Da "Nova República" até a atualidade}

Esse período foi marcado inicialmente por uma grande movimentação em prol das eleições diretas para a I'residência. Com a reorganização das forças políticas, surgiu a Aliança Democrática. que impediu as eleições diretas, e elegeu através da Câmara, um novo Presidente - Tancredo Neves e, como seu vice, José Ribamar Sarney.

Com a morte precoce de 'Tancredo, Jose Ribamar Sarney assumiu o posto presidencial, tendo início a chamada "Nova República". Na tentativa de conter a grande crise inflacionária vivenciada pelo país, foram propostos vários planos econômicos, que pouco transformaram a realidade econômica e social da nação, ainda privilegiando os setores mais ricos, em detrimento da maciça população brasileira.

Com o início desse governo de "transição", desencadearam-se no setor saúde, diferentes medidas que tinham o objetivo de alterar as políticas que privilegiavam a atenção privatizante em detrimento das ações do setor público.

$O$ processo de reforma sanitária, desencadeado por intelectuais e profissionais do Movimento Sanitário, impulsionava à realização da VIII Conferência Nacional de Saúde. Em decorrência desse processo, em 1986, o Ministério da Saúde convocou a VIII ('onf'erência Nacional da Saúde. Ao contrário 
das Conferências de Saúde que hav iam sido convocadas ató então, e que discutiam questões de carater essencialmento teenico, a VIII inovou, no que toca à escolha da temática - Direito a Saúde. Sistema de Saúde o Pinanciamento -, à participação da sociedade civil o ao processo preparalório que envolveu profissionais da saúde, intelectuais usuários e membros de partidos políticos e sindicatos (BRASIL, 1986).

Os debates que so travaram no decorrer da VIII Conferência colocaram a tona as políticas do saúdo como questions a serem discutidas pelo coletivo, mareando contunden temente a história da saúde no Brasil. uma vez que definiu um Programa para a Reforma Sanitária.

Além disso, a VIII Conferência representou um avanço téenico e um pacto político, ao propor a criaşão do Sistema Único de Saúde (SUS), tendo como diretrizes: a universalidade. a integralidade das açōes e a participação social, além de ampliar o conceito do saúde colocando-o como um direito dos cidadãos e um dever do Estado. Entretanto. cabe explicitar queo Estado se antecipou a implementaça do SUS. criando por decreto o Sistema Unificado e Descentralizado de Saúde (SUDS). que incluía a redução da máquina previdenciária do nível estadual. a transferência dos serviços de saúde para os estados e municípios o o estabeleximento de um gestor único da saúde em cada esfera de governo. Alom disso a implementacão do SUUSS dependia do grau de compromisso dos governantess.

O processo de mobilização da sociedade teve continuidade nos trabalhos de elaboração da nova constiluição democrálica. que culminou com a aprovação de um capítulo inédito da Constituição. que vorsava sobre a saúde no qual se refletia, em parte. o pensamento e a luta do movimento sanibário (ESCOREL, 1993).

Os principais pontos aprovades na (Yarla Magna do 1988 foram: o direito universal à saúde; a saúde como um dever do listado: a constituição do SUS, integrando todos os scrviços públicos em uma rede: alóm da preservação dos princípios aprovados pela VIII Conlêrência o a participação do setor privado no SUS de forma complementar. bom como a proibição da comercialização de sangue e de seus derivados.

Apesar dos avanços alcançados, algumas questões permaneceram indefinidas tais como. o financiamento do setor saúde, a política de medicamentos e as ações no âmbito da saúde do trabalhador. Há ainda que ressaltar que permaneceu intocável o paradigma do modelo assistencial centrado na assistência médica individual e, portanton. na ligura do médico.

Com a convocação das eleiçôes em 1989. no contexto de uma crise econômica avassaladora, tomou posse o presidente fernando Collor de Melo. Esse governo se restringiu, no campo da saúde, à adosão explícita da política neoliberal, cujos elementos básicos que a norleiam são: a desvalorização da moeda, a liberalização do comércio exterior a redistribuição da riqueza e receita governamental, a 
redução do déficit público, a redução do emprego público, a privatização, o controle salarial, a eliminação do controle de preços, o cumprimento de parcelas de pagamento da dívida externa e a priorização das exportações, com a queda de qualidade do sistema público (ROSSI, s/d).

O resultado desse processo comecou a se expressar através da oferta de servicos altamente discriminatória, seletiva para os diferentes cidadãos, segundo a sua inserção social e fixada na atenção médica.

Entretanto, mesmo face a esse cenário, a sociedade civil não reagiu prontamente. Segundo NORONHA; LEVCOVITZ (1994), a derrota do Partido dos Trabalhadores, que representava a articulação das forças progressistas, impeliu ao arrefecimento da cena política nacional "de todos os setores comprometidos com o SUS".

Não há dúvida de que a opção neoliberal que visa reduzir o papel do Estado e a remeter a regulação da saúde para o âmbito privado, deve ser analisada com muito cuidado pois, dentre outros argumentos, encontram-se experiências de âmbito internacional, como Chile e México, que evidenciam que os mecanismos de mercado apontam para a ineficiência, a ineficácia e a desigualdade crescentes (LAURELL, 1995).

Como pode se verificar, estava em cena um evidente processo para o impedimento do avanço da implementação do SUS. Como fruto disso, o governo sistematicamente adiou a convocação da IX Conferência Nacional da Saúde, bem como a regulamentação da Lei Orgânica da Saúde (Lei 8080), a qual teve sua aprovação após amploprocesso de mobilização (BRASIL, 1991). Mesmo assim, ela sofreu importantes alteraçôes decorrentes de vetos do Presidente que foram negociados e parcialmente recuperados na Lei no. 8142.

Dos 9 vetos de Collor à Lei 8080, os mais importantes foram: o que instituía as conferências e os conselhos de saúde como instâncias colegiadas e reprèsentativas para formular e propor estratégias, além de exercer controle sobre a execução das políticas de saúde; a não extinção dos escritórios regionais do INAMPS; a transferência da verba direta para os Estados e Municípios; a obrigatoriedade de planos de carreiras, de cargos e salários para o SUS em cada esfera de governo e a fixação de pisos nacionais de salário.

Como fruto de pressões intensas a Lei 8142 recuperou a transferência automática de recursos e a questão da participação e controle sociais, mas não tocou na questão da carreira, mantendo o SUS com uma série de vínculos empregatícios diferenciados nos serviços de saúde.

A IX Conferência Nacional de Saúde foi viabilizada somente em agosto de 1992, tendo sido considerada por muitos, como um processo de maior caráter mobilizatório que o anterior, na medida em que contou com a participação de mais de 5 mil pessoas. Os temas discutidos foram: Sociedade, Governo e Saúde, Seguridade Social, Implementação do SUS e Controle Social. O seu relatório final reiterou as proposições da VIII Conferência e, na realidade, tornou evidente 
a palavra de ordem: "Cumpra-se a Lei", exigindo a operacionalização da VIII Conferência, no que toca à implementação do Sistema Único de Saúde (BRASIL, 1992).

Cabe enfatizar que a IX Conferência ocorreu impregnada pela comoção social que tomava conta do país frente às evidências de corrupção, nas quais Collor estava envolvido. Meses depois, a sociedade civil festejou o "impeachment" do presidente, fenômeno que trazia no seu bojo a possibilidade de volta à democracia e de resgate da cidadania.

Mesmo com a grande movimentação política por parte da sociedade, após esse processo a reação governamental, especialmente em nível federal foi muito "tímida e insuficiente diante das demandas crescentes. O patamar mínimo dos benefícios previdenciários, sobretudo das aposentadorias, é garantido por algum tempo, apesar das pressões (ainda vigentes) sobre o salário mínimo (...). Na área da saúde o caos se instala com uma brutal redução dos recursos de custeio e uma completa paralisação nos investimentos em manutenção e ampliação da rede de serviços. A saúde é seguramente o setor onde o retrocesso se torna mais visível em todos os sentidos" (SOARES, 1995).

A título de ilustração veja-se que, ao final da década de 80 , cerca de $65 \%$ das unidades de saúde que prestavam assistência, pertenciam ao setor público. No que diz respeito às instituições hospitalares, esse montante era de $19,6 \%$, sendo que $77,1 \%$ dessas instituições pertenciam à rede privada (IBGE/AMS, 1989). No que se refere ao gasto em saúde, em 1990, era de US\$132/habitante (incluindo-se o setor privado), sendo que, somente $2,8 \%$ do PIB, ou seja, US\$ $88 /$ habitante relacionava-se ao gasto do setor público (WORLD BANK, 1990). Isto significa um gasto exíguo, quando comparado ao gasto de outros países e, o que é mais importante, de baixíssimo impacto no sentido da mudança dos perfís epidemiológicos.

Por outro lado, segundo CARVALHO (1993) o modelo assistencial que vimos seguindo, inspirado nos moldes americanos "tem gasto $\$ 3250$ per capita s6 em saúde (quase o dobro de nosso PIB per capita) e ainda deixa sem assistência 40 milhões de americanos. Nem de longe, no cômputo mundial, figura ele como o melhor tipo de assistência".

Na realidade, o que se coloca para o país no final dos anos 80 e anos 90 é o embate de duas correntes sobre o Estado: a concepção neoliberal que advoga o Estado mínimo e o mercado como principal agente regulador da ordem econômica e de outro, a concepção da necessidade da presença de um Estado democrático forte, demandado pelas políticas de ajuste estrutural e pelas desigualdades sociais (COHN, 1995).

Lamentavelmente, parece que o neoliberalismo vem assumindo maior força nesse embate. $\mathrm{Na}$ btica do neoliberalismo não se admite o conceito de direitos sociais; a condição de mercadoria da força de trabalho é reforçada, assim como a mercantilização dos bens sociais. 
Sem dúvida nenhuma, os anos 90 herdaram da década de 80 , um aumento da dívida social da nação. O Estado tem cada vez menos respondido às demandas, "seja pela diminuição de sua capacidade de gastos seja pela ausência de um novo bloco de poder capaz de dar governabilidade na medida em que viabilize uma nova estratégia de desenvolvimento com democracia para o Brasil" (FIORI; KORNIS, 1994).

No Município de São Paulo, um fato recente, que corporifica a opção pelo modelo neoliberal foi a proposição do Plano de Assistência a Saúde (PAS), pelo governo do Município. Esse Plano propõe a criação de cooperativas médicas por regiões do município, reforçando o padrão médico-assistencialista e curativo, com ênfase na produtividade. Apesar de ser inconstitucional, foi aprovado em outubro de 1995, pela Câmara Municipal.

\section{7 - Considerações Finais}

Dentro desse quadro evidencia-se que, atualmente, o que se tem na área da saúde é a aplicação do princípio da universalização excludente. O setor privado abarca cerca de 1/3 da população brasileira e, de fato, não há um sistema único, uma vez que coexiste o setor privado e o setor público, sendo que a qualidade da assistência difere segundo os distintos estratos sociais. (O sucateamento do setor público é evidente, com uma desastrosa é acelerada desativação de leitos hospitalares expulsando a clientela deste setor para o privado.

Conforme FIORI (1993), "na década de 80 o Brasil experimentou 8 planos de estabilização econômica, 4 diferentes moedas, 11 índices distintos para cálculo da inflação, 5 congelamentos de preços e salários, 14 políticas salariais, 18 mudanças nas regras de câmbio, 54 mudanças nas regras de controle de preços, 21 propostas de negociação da dívida externa e 19 decretos governamentais de austeridade fiscal. No entanto, nenhuma dessas medidas resultou numa política efetiva que redundasse em transformações estruturais que modificassem o cenário ora existente.

A implementação do modelo econômico neoliberal, como dito anteriormente, põe em evidência a exclusão social, advogada por ESCOREL (1993) como: "a impossibilidade de realizar plenamente a condição humana, é não poder ser um cidadão de sua pólis. Essa exclusão é distinta da abolição de direitos políticos e da supressão do espaço público levado a cabo pelos regimes autoritários, despóticos e ditatoriais. É uma exclusão que não apenas impossibilita o exercício das potencialidades máximas da condição humana, como ainda reduz os indivíduos à condição de animal laborans, cuja única ação é sua preservação biologica".

A aproximação à virada do século, nos coloca diante de mudanças nos perfís epidemiológicos que se expressam pelo aumento da expectativa de vida, o 
que significa um maior contingente de pessoas no grupo da terceira idade e que por isto requerem assistência especializada. Além disso, o processo de transição epidemiológica evidencia que, na verdade, se acumulam as doenças degenerativas às doenças infecto-contagiosas. Esse conjunto, ao lado do inegável desenvolvimento tecnológico, que impulsiona a aplicação de intervenções em saúde caras, complexas e, frequentemente, desnecessárias, é acompanhado da crescente medicalização e da distribuição desigual dos profissionais de saúde no território brasileiro.

Nesse contexto, o que se coloca na realidade são projetos de cunho ideológico, político e técnico distintos: o projeto neoliberal e o projeto da reforma sanitaria, que ainda busca sobreviver, reagindo contra o primeiro. Ao tentar resgatar os pressupostos contidos na Constituição Brasileira, de que a saúde é um direito de todos e um dever do Estado, cabe aos cidadãos optarem pela defesa de um dos projetos acima mencionados, não sem antes ter claro de que a exclusão social, que vem tomando conta da sociedade brasileira, é fruto inegável doprojeto econômico do neoliberalismo. Assim, é fundamental que se tenha clareza de que e impossível superar a crise sem a presença de um Estado forte que aponte para a eficiência, a eficácia e para a equidade crescentes.

A necessidade de proceder à finalização dessa exposição faz com que coloquemos um ponto final aqui. É evidente no entanto, que outros fatos relevantes no âmbito político-econômico-social e de saúde já estão tendo lugar, e que devem ser objeto de registro e análise para dar resposta às demandas de constituição da memória de nosso país.

BERTOLOZZI, M.R.; GRECO. R.M. Health politics in Brasil: historical review and perspectives.

Rev.Esc.Enf.USP,v. 30, n.3, p. 380-98, dec. 1996.

Authors presents an evolution of the public health's politics in Brasil through a critical review of the historical process. Besides this they call to the importance of this issue in the undergraduate curricular in nursing.

UNITERMS: Health politics. History of health in Brasil.

\section{REFERÊNCIAS BIBLIOGRÁFICAS}

ALENCAR, F. et al. História da sociedade brasileira. Rio de Janeiro, Ao Livro Técnico S.A., 1985.

BRAGA, J. C. de S. ; PAULA, S. G. de Saúde e Previdência - Estudos de política social. São Paulo, CEBES/HUCITEC, 1987. 
BRASIL. Ministério da Saúde. Assessoria de Comunicação Social. Lei Orgânica de Saúde. $2^{a}$ ed. Brasília, 1991.

BRASIL. Ministério da Saúde. Relatório final da VIII Conferência Nacional de Saúde. Brasília, 1986.

BRASIL. Ministério da Saúde. Relatório Final da IX Conferéncia Nacional de Saúde. Brasília, 1992.

BUSS, P. M. Saúde e desigualdade: o caso do Brasil. In: BUSS. P.M.: LABRA. M.E. (org.). Sistemas de Saúde: continuidades e mudanças. São Paulo. Hucitec/Fiocruz, 1995. p.61-102.

CARVALHO, G. de C. M. O movimento atual do SUS... a ousadia de cumprir e fazer cumprir a lei. Saúde sociedade. v.2, n.1, p.9.24, 1993.

COHN, A. Mudanças económicas e políticas de saúde no Brasil. In: LAURELL, A. C. (org.). Estado e políticas sociais no neoliberalismo. São Paulo, Cortez. 1995. p. 225-44.

CORDEIRO, H. A. As empresas médicas: um estudo sobre as transformaçסes capitalistas da prática médica no Brasil. São Paulo, 1981. Tese (doutorado) - Faculdade de Medicina, Universidade de São Paulo.

EGRY, E. Y. Desafios teórico-metodológicos para a intervenção práxica da enfermagem em saúde coletiva. Såo Paulo, 1994. 205 p. Tese (livre-docência) - Escola de Enfermagem, Universidade de Så Paulo.

ESCOREL, S. Reviravolta na saúde: origem e articulaçăo do movimento sanitário. Rio de Janeiro, 1993. Tese (mestrado), ENSP/Fiocruz.

FIORI, J. L. Para uma economia politica do Estado brasileiro. São Paulo. IESP/ FUNDAP, 1993.

FIORI, J. L.; KORNIS, G. E. M. Além da queda: economia e politica numa década enviesada. In: GUIMARAES,R.; TAVARES,R. (org.). Saúde e sociedade no Brasil - anos 80. Rio de Janeiro, Relume do Mará, 1994. p. 1-42.

FUNDAÇÃO INSTITUTO BRASILEIRO DE GEOGRAFIA E ESTATÍSTICA. Estatísticas de Saúde. Assistência Médico Sanitária. Rio de Janeiro, IBGE. 1989. v. 14.

IYDA, M. Cem anos de saúde pública: a cidadania negada. Sao Paulo, Universidade Estadual Paulista, 1994.

LAURELL, A. C. (org.) Estado e políticas sociais no neoliberalismo. São Paulo, Cortez, 1995.

MENDES, E. V. (org). Distrito sanitário: o processo social de mudança das políticas sanitárias do Sistema Único de Saúde. São Paulo, HUCITEC/ABRASCO, 1993.

NORONHA, J. C. D.; LEVCOVITZ, E. AIS-SUDS-SUS: Os caminhos do direito à saúde. In: GUIMARAES,R.; TAVARES,R.(org). Saúde e sociedade no Brasil - anos 80 . Rio de Janeiro, Relume do Mará, 1994.p. 73-111. 
OLIVEIRA, J.A.de A.; TEIXEIRA, S.M.F. (Im) previdéncia social: 60 anos de história da previdência no Brasil. Petrópolis, Vozes, Abrasco, 1985, 360p.

POSSAS,C. de A. Saúde e trabalho - a crise da previdéncia social. Rio de Janeiro, Graal, 1981.

QUEIROZ, V. M.; EGRY, E. Y. Bases metodolbgicas para a assistencia de enfermagem em saúde coletiva, fundamentadas no materialismo histórico e dialético.Rev. Bras. Enf., v.41, n.1, p.26-33, 1988.

QUEIROZ, V. M. ; SALUM, M. J. L. (a) Síntese do tema da primeira oficina de trabalho: processo de produçăo em saúde. In: SEMINÁRIO DE REDIRECIONAMENTO DA PRÁTICA DE ENFERMAGEM NO SUS, 1., Såo Paulo, 1994./Mimeografado/.

QUEIROZ, V. M. ; SALUM, M. J. L. (b) Síntese do tema da segunda oficina de trabalho: processo saúde-doença. In: SEMINÁRIO DE REDIRECIONAMENTO DA PRÁTICA DE ENFERMAGEM NO SUS, 1., Så Paulo, 1994. Mimeografado/.

QUEIROZ, V. M. ; SALUM, M. J. L. (c) Síntese do tema da terceira e quarta oficinas de trabalho: a prática da enfermagem no processo de produção em saúde e processos de trabalho em enfermagem. In: SEMINÁRIO DE REDIRECIONAMENTO DA PRÁTICA DE ENFERMAGEM NO SUS, 1., São Paulo, 1994. Mimeografado/.

ROCHA, J. S. Y. O movimento da reforma sanitária no Brasil. Previdéncia Dados. v.3, n.2, p.5-11, 1988.

ROSEN, G. Uma história da saúde pública. São Paulo, HUCITEC/ Ed. UNESP, ABRASCO, 1994.

ROSSI, S. S. Desenvolvimento de políticas de saúde nos anos 80: o caso Brasileiro. Sao Paulo. Escola de Administração de Empresas de São Paulo da Fundaçăo Getúlio Vargas. I Mimeografado/.

ROSSI, S. S. A constituiçăo do sistema de saúde no Brasil. São Paulo, 1980. /Mimeografado/.

SOARES, L. T. R. Ajuste neoliberal e desajuste social na América Latina. Campinas, 1995. 445p. Tese (doutorado) - Instituto de Economia, Universidade Estadual de Campinas.

TEIXEIRA, S.M.F. Política de saúde na transiçáo conservadora. Rev. Saúde Debate. n.26, p.42-43, 1989.

WORLD BANK. Brazil: the new challenge of adult health. Washington, World Bank, 1990. 